\title{
Community risk perception on healthcare wastes in hospitals and health centres of Eastern Ethiopia
}

\author{
Tadesse Alemayehu ${ }^{1, *}$, Alemayehu Worku ${ }^{2}$, Nega Assefa ${ }^{3}$ \\ ${ }^{1}$ College of Health and Medical Sciences, Haramaya University, P.O. Box 1517, Harar, Ethiopia \\ ${ }^{2}$ School of Public Health, Addis Ababa University, P.O. Box 7117, Addis Ababa, Ethiopia \\ ${ }^{3}$ College of Health and Medical Sciences, Haramaya University, P.O. Box 235, Harar, Ethiopia
}

\section{Email address:}

tadessewon@yahoo.com (T. Alemayehu), tadessewon@ hotmail.com (T. Alemayehu), alemayehuwy@yahoo.com (A. Worku), negaassefa@yahoo.com (N. Assefa)

\section{To cite this article:}

Tadesse Alemayehu, Alemayehu Worku, Nega Assefa. Community Risk Perception on Healthcare Wastes in Hospitals and Health Centres of Eastern Ethiopia. Science Journal of Public Health. Vol. 3, No. 1, 2015, pp. 37-43. doi: 10.11648/j.sjph.20150301.17

\begin{abstract}
Background: Indiscriminate waste disposal by many healthcare facilities pose serious health hazard to the inhabitants in general and people living around health care facilities in particular. Human scavengers collecting second hand objects for reselling could be a channel for speading disease causing organisms. In addition, burning of wastes in small size incinerator at a low temperature releases many toxic gases causing health effects for people living around the facilities. The objective of the study was to assess risk perception of people living around health facilities about healthcare wastes. Methodology: A cross sectional study was conducted on 438 people in the eastern part of Ethiopia, from August to November 2013. Samples were taken by proportionate allocation to the size of people living within one km radius of 25 health facilities. Questionnaire was administered by a face-to-face interview. Risk perception was classified using a three-point Likert scale from low to high risk. Data were analyzed using STATA software. Bivariate and multi-variable analyses were carried out to determine correlates of risk perception. Result: The magnitude of risk perception for sharp, infectious/pathological wastes and expired drugs was $87 \%, 93.6 \%$, and $73.1 \%$, respectively. Individuals from urban areas have about 3 times higher odds of increased perceived risk than from rural areas $(\mathrm{AOR}=3.02,95 \% \mathrm{CI}$ : 1.08-4.32, $\mathrm{P}=0.006)$. On the other hand, people living around the hospitals have 2.5 times higher odds of increased perceived risk than those people living near to health centers $(\mathrm{AOR}=2.45,95 \% \mathrm{CI}: 0.19-3.04, \mathrm{P}=0.000)$. Conclusion and recommendation: People involved in this study have high perceived risk for hazardous (infectious and sharp) wastes which might be due to indiscriminate discharges of wastes by the nearby health facilities. It is therefore advisable to dispose wastes in a proper manner in order to minimize public concern.
\end{abstract}

Keywords: Health Facilities, Surrounding Communities, Risk Perception, Healthcare Wastes, Hospital, Health Center, Ethiopia

\section{Background}

Indiscriminate waste disposal by many health facilities pose serious health hazard to the inhabitants in general and people living around the healthcare facilities in particular (Bassey et al. 2006). Other risks of environmental pollution and health effects of the public, patients, and professionals are among the main concerns of improperly managed healthcare wastes (Umar \& Yaro 2009).

Unfenced waste disposal places inside many health facilities are visited by animals and human scavengers (Gupta \& Boojh 2006) where they might spead disease causing organisms to people in the surrounding communities. Human scavengers are working in the dumping places where they collect contaminated materials for reselling. While doing this, they are at high risk of injury from sharp instruments and direct contact with infectious materials (Cheng et al. 2009). They further spread communicable diseases through recyclable low price products in the population, increasing the risk of disease and contamination (Bassey et al. 2006). In many resource poor countries where illegal dumping of healthcare wastes is commonly practiced, children are one of the population groups who are at risk for exposure to blood born viruses while playing through discarded syringes and needles (de Waal et al 2005).

The other major problem of healthcare waste disposal in developing countries is the burning of the wastes in small size incinerator with a temperature below $800^{\circ} \mathrm{C}$ (Ruoyan et al. 
2010). Incineration was considered as a best waste treatment option especially for healthcare wastes for many years because of the belief in most professionals that it is the easiest and most effective way to destroy disease causing organisms (Mbongwe et al. 2008, Gupta et al. 2009). But later on, as healthcare wastes contain various materials such as plastics, blood and Intravenous (IV) fluid bags and so on, burning of these materials releases many toxic gases such as dioxins, furans and other toxic pollutants which exposes people to more health and health related risks (Gupta et al. 2009, Mbongwe et al. 2008, Gupta \& Boojh 2006, Ruoyan et al. 2010).

In a study conducted in Bangladesh to assess effects of wastes healthcare on human scavengers who are melting plastics, a self-reported disease symptoms were identified as headache, heaviness of head, dizziness, and fatigue, difficulties in concentration, tiredness, itching, eye burns, skin rash and coughs and had suffered from minor or major burns and skin inflammation. In addition, 56\% reporting that they had experienced accidental injury by sharp materials. Furthermore, scavengers were observed selling items like syringes, saline bag, plastic materials, cans, metals, expired drugs directly to nearby pharmacies from medical waste (Patwary et al. 2011b).

Researchers in Cameron have conducted a study on health professionals to assess complaints of people regarding waste disposal who are living around the hospitals. In this study, $31.2 \%$ of health professionals reported having heard of complaints or concerns and the most frequently reported concerns were difficulty of breathing during the burning of healthcare waste and the foul smell from decomposing tissues. Health professionals have also heard peoples' concern regarding access by children to the dump sites, where they scavenge for contaminated syringes and intravenous sets (Mochungong et al. 2010).

In a five year study in Asian countries to review contamination of persistent organic pollutants (POPs) in human breast milk, data from India showed Dioxine and Related Compounds (DRCs) were detected in all the samples of human breast milk collected from the residents around the open dumping sites. In this study large open dumping sites of wastes were identified as the prime source of DRCs' pollution. Its concentration in human breast milk and soils from the dumping site were significantly higher than those from the reference sites (Tanabe \& Kunisue 2007).

The impact of waste generated from the healthcare facilities on human health and the environment has often not been given significant attention from either the affected people or the concerned authorities (Gupta \& Boojh 2006). On the other hand, there is limited knowledge on the health effects and symptoms associated with individuals exposed to healthcare wastes (Patwary et al. 2011a). Though many have pointed out the potential health risks of improper healthcare waste management (HWM) on people surrounding health facilities (Tanabe \& Kunisue 2007, Mochungong et al. 2010, Patwary et al. 2011b, Patwary et al. 2011b, Gupta et al., 2009, Mbongwe et al. 2008, Gupta \& Boojh 2006, Ruoyan et al. 2010), the complaints of those inhabitants are not well documented and quantified.

In Ethiopia, the effects of healthcare wastes on people living surrounding the health facilities and on the environment are unknown. People's attitude toward these wastes and particularly to the waste disposal and potential effects arising from it is not also well documented. This study assessed perception of risks of healthcare wastes by people living in the surrounding areas of health centers and hospitals.

\section{Material and Methods}

This study was conducted in Harari Region, Dire Dawa Administration, and east and west Hararghea zones of Oromia Regional State, eastern Ethiopia, from August to November 2013. According to the data obtained from the respective health offices, there are a total of 195 public health facilities (hospitals and health centers) in the study area. This cross-sectional study was done on people living in the surrounding areas of 25 (9 hospitals and 16 health centers) of the health facilities.

The source population for this study was all people who live within one $\mathrm{km}$ radius of the healthcare facilities. To delineate a one $\mathrm{km}$ radius from a health facility, data collectors used their own judgmental decisions for determining the distance. After the data collectors delineate the area, all households within this area were registered to generate the sampling frame. A household member whose age is greater than 18 years old was eligible to participate in the study.

Because of lack of similar studies, a $50 \%$ proportion (people who have complaint on healthcare wastes) was taken while calculating the sample size. The calculated sample size was 384 , and with a $15 \%$ none response rate, the final sample became 442 . Samples were taken by proportionate allocation to the size of people living within one $\mathrm{km}$ radius of the health institutions. First, all households who are living within one km radius of health centers and hospitals were registered. Then, the total sample was distributed in the selected health facilities proportionally based on the total number of people registered.

Questionnaire was used to collect data. It was prepared for this particular purpose and administered by a face-to-face interview method. The main parts covered by the questionnaire were demographic characteristics (age, educational level, occupation), distance of the residence from the healthcare facility, knowledge of the internal area of the facility and perceived risks of improper waste management and the different waste categories.

The questionnaire was pretested among individuals living in the surrounding health facilities which are not included in the study but with a similar conditions. For the purpose of maintaining the quality of the data, all data collectors and supervisors attended a three days training (two days before and one day after the pretest), they strictly follow the field and ethical intervention manuals; and supervision and checking filled questionnaire were made to ensure their completeness and consistency. All data collectors were diploma level health professionals and the supervisors have a bachelor degree working at Haramaya University. 
Ethical clearance was obtained from IRB of the College of Health and Medical Sciences, Haramaya University. For the purpose of facilitating field work, we have asked and secured permission from the regional, zonal, district and local administrations. Through a written consent, participants were requested for their willingness to participate to this study. They were also informed that they have a right to withdraw at any time during the data collection and at the same time assured that their responses will be kept confidential and be used only for this study purpose.

The dependent variable for this study was perceived risk about healthcare wastes. During data collection, risk perception was measured using a five-point Likert scale anchored by 1 (the lowest) to 5 (the highest perception of risk). These five categories include (1) no risk, (2) low risk, (3) medium risk, (4) high risk, and (5) very high risk. People surveyed chose one of these categories according to the question and their perception of the risk. During analysis, because values at the either side of the scale have fewer observations (for no and very high risk), it was reclassified into three categories as (1) low risk, (2) medium risk and (3) high risk. This classification was based on combining the two end levels into the nearest category. Accordingly, no and low risk were combined and labeled as low risk, at the same time, high and very high were also combined and named as high risk. Data from the questionnaires was stored and coded in a database for subsequent analysis. It was checked for consistency and completeness, and then statistically analyzed using STATA version 12 software. First descriptive statistics was carried out and both bivariate and multi-variable analyses were done. During bivariate analysis, variables with $\mathrm{p}<0.3$ were retained for the final analysis by ordinal logistic regression model.

\section{Results}

\subsection{Socio Demographic Characteristics of Respondents}

Table 1. Socio-demographic characteristics of respondents who live around health facilities in the eastern Ethiopia, 2014

\begin{tabular}{|c|c|c|}
\hline Variable & Number & $\%$ \\
\hline \multicolumn{3}{|l|}{ Age group } \\
\hline $15-24$ & 110 & 25.1 \\
\hline $25-34$ & 154 & 35.2 \\
\hline $35-44$ & 94 & 21.5 \\
\hline $45-54$ & 41 & 9.4 \\
\hline $55-64$ & 21 & 4.8 \\
\hline $65-74$ & 15 & 3.4 \\
\hline $75-84$ & 3 & 0.7 \\
\hline \multicolumn{3}{|l|}{ Distance (in meters) } \\
\hline $10-200$ & 299 & 70.4 \\
\hline $201-400$ & 82 & 19.3 \\
\hline $401-600$ & 23 & 5.4 \\
\hline $601-800$ & 5 & 1.2 \\
\hline $801-1000$ & 16 & 3.8 \\
\hline Single & 100 & 22.9 \\
\hline Married & 277 & 63.4 \\
\hline Divorced & 24 & 5.5 \\
\hline Widowed & 36 & 8.2 \\
\hline \multicolumn{3}{|l|}{ Religion } \\
\hline Muslim & 319 & 73.8 \\
\hline Orthodox Christian & 97 & 22.5 \\
\hline Protestant & 13 & 3.0 \\
\hline Catholic & 3 & 0.7 \\
\hline \multicolumn{3}{|l|}{ Educational status } \\
\hline Illiterate & 192 & 43.9 \\
\hline Write \& read & 27 & 6.2 \\
\hline Primary school (1-8) & 87 & 19.9 \\
\hline Secondary school (9-12) & 91 & 20.8 \\
\hline Diploma \& above & 40 & 9.2 \\
\hline Farmer & 64 & 14.6 \\
\hline Government employee & 64 & 14.6 \\
\hline Student & 40 & 9.2 \\
\hline Merchant & 103 & 23.6 \\
\hline Daily labourer & 14 & 3.2 \\
\hline Others & 8 & 1.8 \\
\hline
\end{tabular}


Four hundred thirty eight $(99 \%)$ have responded to this study. The mean age of respondents was 33.1 years with standard deviation of 12.8 years. The average distance respondents live from the health facility was $475.4 \mathrm{~m}$ with a minimum of $10 \mathrm{~m}$ to a maximum of $1 \mathrm{~km}$. Majority, 331 $(75.6 \%)$ of the respondents have reported that they have children. The number of children respondents has ranged from 1 to 10. Educational status records of the respondents showed, $192(43.9 \%)$ are illiterate while 27 (6.2\%) can read and write (Table 1).

\subsection{Knowledge about the Nearest Health Facility}

Four hundred thirty one $(98.4 \%)$ knew the compound of the nearest health facility. Furthermore, 295(68.8\%) of them knew the waste disposal place of the facilities. Rating the hygiene/sanitation of the inside part of these facilities with a five-level Likert scale, from excellent to worse, seemed that most of the respondents' rate was concentrated in the middle of the scale. Accordingly, more than $85 \%$ of the rates were given for good and very good for each of the items questioned (Table 2). On the other hand, people's knowledge on the types of wastes produced was assessed. The number of people who knew the production of infectious waste in the nearest health facility was $153(35.1 \%)$ where as $283(42 \%)$ responded for sharp wastes. At the same time, they were asked a general question about what effect does improper disposal of healthcare waste could have. The result showed that $242(55.4 \%), 219(50.1 \%)$ and $61(14 \%)$ have responded it creates nuisance, causes infection and water pollution respectively. But, the number of people responded as it causes soil pollution was only $22(5.0 \%)$.

Table 2. Attitude of people about the HWM of the nearest HF in the eastern Ethiopia, 2014

\begin{tabular}{llllll}
\hline Attitude Questions & Excellent & Very good & Good & Bad & Worse \\
\hline How do you see the hygiene of inside the compound? & $33(7.7)$ & $285(66.3)$ & $100(23.3)$ & $11(2.6)$ & $1(0.2)$ \\
How do you see the hygiene of outside the compound? & $27(6.2)$ & $242(55.7)$ & $138(31.8)$ & $25(5.7)$ & $2(0.5)$ \\
How do you see the HWM system & $17(3.9)$ & $245(56.5)$ & $157(36.2)$ & $14(3.2)$ & $1(0.2)$ \\
How do you see the waste disposal method? & $18(4.4)$ & $183(44.4)$ & $188(45.6)$ & $21(5.1)$ & $2(0.5)$ \\
\hline
\end{tabular}

People are living at different distance from the health facilities. In general, $299(70.4 \%)$ of the respondents were living within 200 meter from a health facility. Regarding the effect of wastes, $30(6.9 \%)$ and $14(3.2 \%)$ of the respondents knew some type of potential health hazards because of improper disposal of wastes from nearby health facility on their families and neighbors respectively. Out of the listed complaints, the frequently mentioned risk was needle stick injury among adults and children who salvage objects they have found around the health facility's open dumping sites. In addition, people reported having frequent headache, common cold and there were few who perceived as they developed chronic health problems such as asthma.

\subsection{Risk Perception of People about Healthcare Wastes}

The perception of people on the risks of healthcare wastes was assessed and presented by a three-point Likert scale from low to high risk. Most of the respondents have high perceived risk for all type of wastes. Accordingly, 87\%, $93.6 \%$ and $73.1 \%$ of the respondents have rated high risk for sharps, infectious/pathological wastes and expired drugs respectively (Table 3 ).

Table 3. Respondent's perception about the effects of the different types of wastes in the eastern Ethiopia, 2014

\begin{tabular}{|c|c|c|c|}
\hline Questions & Low risk $(\%)$ & Medium risk (\%) & High risk $(\%)$ \\
\hline How do you see the health effects of refuse? $(n=438)$ & 28.8 & 44.1 & 27.2 \\
\hline How do you see the health effects of sewage? $(n=438)$ & 18.9 & 29.5 & 51.6 \\
\hline How do you see the health effects of healthcare general wastes? $(n=437)$ & 27.7 & 29.7 & 42.6 \\
\hline How do you see the health effects of sharps? $(n=438)$ & 4.6 & 8.4 & 87.0 \\
\hline How do you see the health effects of infectious wastes? $(n=436)$ & 3.0 & 3.4 & 93.6 \\
\hline How do you see the health effects of expired drugs? $(n=431)$ & 11.9 & 15.1 & 73.1 \\
\hline
\end{tabular}

Asking whether they saw children in the area playing with syringe with needle, 56 (13\%) have responded yes. On the other hand, $92(21.1 \%)$ of the respondents saw while animals such as dogs entering into the waste disposal place of the nearby health facility. Almost half $(51.1 \%)$ of the respondents saw or heard dogs picked unidentified anatomical waste from the disposal places inside the health facilities. Only 17 (3.9\%) witnessed they have encountered human scavengers selling drugs and other used medical instruments to the surrounding community and $3(17.6 \%)$ reported the case to the nearest police station.

\subsection{Factors Influencing Risk Perception of People about Healthcare Wastes}

In a bivariate analysis, variables such as educational status, living in urban areas and near to hospitals, knowledge of the production of infectious and sharp wastes, knowledge about improper HWM causing nuisance, air, soil, water pollutions, have a statistical significance relationship with people's risk perception. Particularly, those people who have knowledge about improper HWM causing water pollution have 2 time higher risk than those who do not know about water pollution. 
While running the multivariable ordinal logistic regression, some variables were found to be a predictor for peoples' perceived risk. Those who knew the production of sharps wastes in the nearest HF have the odds of having perceived risk decrease by $41 \%$ than those who do not know the production of sharps. As the same time, knowledge of improper HWM which produces nuisance $(\mathrm{AOR}=0.756, \mathrm{CI}$ $=0.034-0.991, \mathrm{P}=0.036)$ and causes infection $(\mathrm{AOR}=2.096$, $\mathrm{CI}=-1.29--0.33, \mathrm{P}=0.001)$ remains an influential factor for increasing perceived risk. On the other hand, the odds of having high perceived risk increases 3 times more for people who lived in the urban than those living in the rural areas $(\mathrm{AOR}=3.02,95 \% \mathrm{CI}: 1.08-4.32, \mathrm{P}=0.006)$. At the same time, people living around the hospital have the odd of increased risk by 2.4 times more than those people living near to health centers $(\mathrm{AOR}=2.45,95 \% \mathrm{CI}: 0.19-3.04, \mathrm{P}=$ 0.000) (Table 4).

Table 4. Factors influencing peoples perceived risk about healthcare wastes in the eastern Ethiopia, 2014

\begin{tabular}{|c|c|c|c|c|c|c|}
\hline & $\mathbf{N}$ & AOR & $\%$ & $95 \% \mathrm{C}$ & & P-value \\
\hline Production of infectious waste & 153 & 1.033 & 3.3 & -0.42 & 0.515 & 0.888 \\
\hline Production of sharps & 183 & 0.586 & -41.5 & 0.045 & 0.603 & 0.011 \\
\hline HWM cause air pollution & 197 & 0.996 & -0.44 & -0.45 & 0.442 & 0.053 \\
\hline HWM cause water pollution & 61 & 0.824 & -17.4 & -0.80 & 0.411 & 0.2 \\
\hline HWM cause Nuisance & 242 & 0.756 & -25.0 & 0.03 & 0.991 & 0.036 \\
\hline HWM cause infection & 218 & 2.096 & 109.6 & 0.29 & 2.20 & 0.001 \\
\hline Living near hospital & 184 & 2.45 & -47.3 & 0.19 & 3.04 & 0.000 \\
\hline Living in urban areas & 292 & 3.02 & 126.0 & 1.08 & 4.32 & 0.006 \\
\hline
\end{tabular}

\section{Discussion}

People's perceived risk about healthcare wastes was assessed with a three-point-Likert scale. They have reported a high perceived risk for infectious and sharp wastes and expired drugs but showed relatively low risks for chemical/pharmaceutical and general wastes. Lennart Sjöberg and colleagues defined risk perception as the subjective assessment of the probability of a specified type of accident happening and how concerned we are with the consequences (Sjöberg et al., 2004). Because people are getting information from different media about the real effects of certain waste types (such as infectious and sharps) and expired drugs, their risk perception rate was found to be high. They perceive risks not only because of their own personal experiences but it is also acquired from others as it is a social and cultural construct reflecting values, symbols, history, and ideology (Weinstein 1989).

People who lived in urban areas and close to hospitals have greater perceived risk than those who live around health centers. Hospitals generate large amount of infectious wastes than a health center (C.E. Da Silvia, 2005). Many hospitals practiced open dumping of wastes including burning their waste in the open air within the hospital premises (Mbongwe et al., 2008). Improper disposal and miss management of large quantities of wastes in hospitals might create discomfort and anxiety for people living in the area. At the same time, if the health facility is not taking appropriate measure on time, this discomfort and anxiety might grow to high perceived risks towards the event - the growing quantities of hazardous waste production and miss management (Bulter \& Mathew 1987, Weinstein 1989).

Though the statistical significant relationship between educational status and perceived risk vanish in the last model, its role in risk perception was important in other studies (Mgbere et al., 2013), Schwarzinger 2010, Poudel-Tandukar
2007). In this study it was also revealed that $192(43.8 \%)$ of the total respondents are illiterate and 164 (37.4\%) earn less than 500 birr per month. Worldwide, there are concerns over the health effects of different hazardous waste disposal options, including open dumping, land filling and incineration that disproportionately impose different health risks in different social groups living in the same area (Martuzzi et al., 2010, Margai 2001). Studies found out that there is a skewed distribution around waste sites, with low-income groups, minorities, uneducated and working-class persons are living in the surroundings of such facilities (Faber \& Krieg 2002). In Europe and US, data also showed there is a relationship between socio-economic statuses (SES), such as social class, education, unemployment, housing, family structure, with localization of solid waste and other polluting facilities (Friends of the Earth 2004, Walker 2003).

More than one in four respondents each reported that they knew healthcare wastes cause air pollution, nuisance and infection, but less than one percent replied for soil and water pollution. Causes of wastes such as nuisance and infection are direct observed effects and the effect on the air might be exhibited while burning of wastes. Associating the effects of healthcare waste to soil and water pollutions for many ordinary people might be difficult. The major effects of indiscriminate discharge of wastes of any type are environmental pollution. Major pollution risks are air, soil and water (But 2008). In addition to this, wastes cause unsightly condition and nuisance. Causing microbiological infection is the other effect of healthcare wastes. Though the risk is low among the general public, viral infections such as HIV/AIDS and hepatitis B and C from improperly managed healthcare waste can cause a great risk of infection through injuries from contaminated sharps (largely hypodermic needles) (Prüss-Ustun et al., 2013). On the other hand, sporadic infections such as cholera could affect people living surrounding health facilities due to open dumping of 
healthcare wastes (Prüss-Ustun et al. 2013).

Some respondents have reported that they knew and heard at least one effect on their families and neighbors resulted from healthcare wastes. Studies in Ethiopian found out that healthcare wastes are dumped in uninspected areas created favorable condition for illegal human scavengers to scramble resalable items (Habtestion et al., 2009, Derebe et al. 2012, Hylamicheal et al. 2011). There is however little information on the effect of such types of business to the community and particularly people living surrounding the health facilities. Infections might be spreading to the community through items used by patients or in contact with their blood and other body fluids (Patwary et al. 2011a). Children are the most vulnerable part of the society exposed to blood born viruses while playing with discarded syringes and needles from illegal dumping places. Two children were HBV surface antigen positive at presentation, which suggests a real risk of HBV spread in South Africa (de Waal 2005).

Half of the respondents either saw or heard animals such as dogs enter into the dumping sites where they picked anatomical wastes (such as body parts, placentas, etc) from the open dumping places inside the health facilities and brought into the community. Healthcare wastes containing such type of wastes which needs special treatment and disposal and overall should be managed separately from other waste types. If these types of wastes are not disposed appropriately, they might be taken out by animals such as dogs which might cause huge public outrage and indignation. In many cultures and religions in Ethiopia human body parts should be given to the patient's family so that they will buried it in cemeteries. If not it will be thrown into placental pits available in many health facilities. However, the construction of such pits is not with the consultation of engineers and has poor ventilation system. They are made water tight in order to protect water and soil pollution, but creates a huge 'noxious' smell when opening the 'pit hole'. Because of this, many waste handlers prefer to dispose to the open pit together with other type of wastes.

In Ethiopia, the effects of healthcare wastes on the health workers, waste collectors, patients and the population nearby are unknown. The level of people's knowledge and their attitude toward these wastes and particularly to the waste disposal and potential effects arising from it is not well documented. In the current study, people who identified healthcare wastes as a potential source of air pollution had a high perceived risks. Though not statistically significance, the number of respondents who identified healthcare wastes as a cause for water and soil pollution was high. In a survey, $59 \%$ of the respondents in Nepal stated that they consider healthcare waste as a major problem (Pokhrel \& Viraraghavan 2005). Al-Yaqout and colleagues carried out a survey on the public perception on the landfill and its public health aspect in Kuwait. The study revealed that $50 \%$ of the respondents were aware of the public health impact of the landfills (Al-Yaqout et al. 2002).

One of the limitations that typically arise in this study was the selection of the appropriate size of the risk zone within which the population is most vulnerable to the effects of healthcare wastes (Margai 2001). With no literature found, it was difficult to identify at what distance away people living from health facilities are at risk of effects from healthcare wastes. It was finally decided based on the researches' judgment not to make the distance too far so that people may not at all feel the risk and not too short so that people who are at risk are missed.

\section{Conclusion and Recommendation}

People involved in this study have high perceived risk for hazardous (infectious and sharp) wastes which might be due to indiscriminate discharges of these wastes by the nearby health facilities. The health authorities should find ways of discriminating hazardous wastes from other wastes and devise ways of discarding them so that they no more create a public health threat. This study attempted to highlight the perceived risks of people of the surrounding community about healthcare wastes. Accordingly, people had high perceived risks for infectious wastes, used sharp objects and expired drugs. There is however a need to ascertain the real effects of wastes with further researches on a different study design and methodological approach.

\section{Acknowledgements}

Authors of this study would like to thank the informants who provide additional information during observation for their time and willingness to supply valuable information. Our acknowledgement extends to Haramaya University for providing fund to conduct this study.

\section{References}

[1] Abubakar U, Abdu Y. Hospital waste management in Katsina state. Bayero Journal of Pure and Applied Sciences 2009, 2(2):22-26

[2] Al-Yaqout AF, Koushki PA, Hamoda MF. Public opinion and siting solid waste landfills in Kuwait. Resource, Conservation and Recycling 2002, 35:215-227.

[3] Bassey BE, Benka-Coker MO, Aluyi HAS. Characterization and management of solid medical wastes in the Federal Capital Territory, Abuja Nigeria. African Health Sciences 2006, 6(1):58-63

[4] Butler G, Mathews A. Anticipatory anxiety and risk perception. Cognitive Therapy and Research 1987, 11(5):551-565

[5] Cheng YW, Sung FC, Yang Y, Lo YH, Chung YT, Li KC. Medical waste production at hospitals and associated factors. Waste Management 2009, 29:440-444. doi:10.1016/j.wasman.2008.01.014

[6] Da Silva CE, Hoppe AE, Ravanello MM, Mello N. Medical wastes management in the south of Brazil. Waste Management 2005, 25:600-605 doi:10.1016/j.wasman.2004.03.002

[7] de Waal N, Rabie H, Bester R, Cotton MF. Mass needle stick injury in children from the Western Cape. Journal of Tropical Pediatrics 2005, 52(3):192-196 doi:10.1093/tropej/fmi094 
[8] Derebe MK, Gelaye KA, Alamdo AG, Trifa ZM. Assessment of the health care waste generation rates and its management system in hospitals of Addis Ababa, Ethiopia, 2011. BMC Public Health 2013, 13:28. doi:10.1186/1471-2458-13-28

[9] Faber DR, Krieg EJ. Unequal exposure to ecological hazards: environmental injustices in the Commonwealth of Massachusetts. Environ Health Perspect 2002, 110(Suppl 2):277-88. doi:10.1093/eurpub/ckp216

[10] Friends of the Earth. Incinerators and deprivation. Briefing. London. Friends of the Earth, 2004. (http://www.foe.co.uk/resource/briefings/incineration_deprivat ion.pdf) (Accessed on: December 9, 2014).

[11] Gupta S, Boojh R, Mishra A, Chandra H: Rules and management of biomedical waste at Vivekananda Polyclinic: A case study. Waste Management 2009, 29:812-819. doi:10.1016/j.wasman.2008.06.009

[12] Gupta S, Boojh R. Biomedical waste management practices at Balrampur Hospital, Lucknow, India. Waste Manage \& Res 2006, 24:584-591. DOI: 10.1177/0734242X06068342

[13] Habtetsion T, Bock A, Noel M, Shanadi Bhat D, Abebe F, Van Roekel, K. Evaluation of injection safety and healthcare waste management in Ethiopia: 2009 First Draft Report, September 2009 edition. Addis Ababa, Ethiopia MMIS for the Office of the Global AIDS Coordinator, and the Department of Health and Human Services/USAID Development. http://pdf.usaid.gov/pdf_docs/PNADR654.pdf (Accessed August 3, 2014).

[14] Haylamicheal ID, Dalvie MA, Yirsaw BD, Zegeye HA. Assessing the management of healthcare waste in Hawassa city, Ethiopia. Waste Manag \& Res 2011, 29: 854-862. DOI: $10.1177 / 0734242 X 10379496$

[15] Margai FL. Health risks and environmental inequity: A geographical analysis of accidental releases of hazardous materials, The Professional Geographer 2001, 53(3): 422-434. doi.org/10.1080/00330124.2001.9628473

[16] Martuzzi M, Mitis F, Forastiere F. Inequalities, inequities, environmental justice in waste management and health. European Journal of Public Health 2010, 20(1):21-26. doi:10.1093/eurpub/ckp216

[17] Mbongw B, Mmerek BT, Magashula A. Healthcare waste management: Current practices in selected healthcare facilities, Botswana. Waste Management 2008, 28:226-233. doi:10.1016/j.wasman.2006.12.019

[18] Mgbere O, Monjok E, Abughosh S, Ekong E, Holstad MM, and Essien EJ. Modeling covariates of self-perceived and epidemiologic notions of risk for acquiring STIs/HIV among military personnel: A comparative analysis. AIDS Behav. 2013, 17(3):1159-1175. doi:10.1007/s10461-011-0126-5.
[19] Mochungong PIK, Gulis G, Sodemann M. Hospital workers' awareness of health and environmental impacts of poor clinical waste disposal in the Northwest Region of Cameroon. Int J Occup Environ Health 2010, 16:53-59

[20] Patwary MA, O'Hare WT, Sarker MH. An illicit economy: Scavenging and recycling of medical waste. Journal of Environmental Management 2011a, 92:2900-2906. doi:10.1016/j.jenvman.2011.06.051

[21] Patwary MA, O'Hare WT, Sarker MH. Assessment of occupational and environmental safety associated with medical waste disposal in developing countries: A qualitative approach. Safety Science 2011b, 49:1200-1207. doi:10.1016/j.ssci.2011.04.001

[22] Pokhrel D, Viraraghavan T. Municipal solid waste management in Nepal: practices and challenges. Waste Management 2005, doi:10.1016/j.wasman.2005.01.020

[23] Poudel-Tandukar K, Nakahara S, Ichikawa M, Poudel KC, Jimba M. Risk perception, road behavior, and pedestrian injury among adolescent students in Kathmandu, Nepal. Injury Prevention 2007, 13:258-263. doi: 10.1136/ip.2006.014662

[24] Ruoyan G, Lingzhong X, Huijuan L, Chengchao Z, Jiangjiang $\mathrm{H}$, Yoshihisa S, Wei T, Chushi K. Investigation of healthcare waste management in Binzhou District, China. Waste Management 2010, 30:246-250. doi:10.1016/j.wasman.2008.08.023

[25] Schwarzinger M, Mohamed MM, Gad RR, Dewedar S, Fontanet A, Carrat F, Luchini S. Risk perception and priority setting for intervention among hepatitis $\mathrm{C}$ virus and environmental risks: a cross-sectional survey in the Cairo community. BMC Public Health 2010, 10:773. doi:10.1186/1471-2458-10-773

[26] Sjöberg L, Moen BE, Rundmo T. Explaining risk perception. An evaluation of the psychometric paradigm in risk perception research. Norwegian University of Science and Technology 2004, Department of Psychology, 7491 Trondheim, Norway. ISBN 82-7892-024-9

[27] Tanabe S, Kunisue T. Persistent organic pollutants in human breast milk from Asian countries. Environmental Pollution 2007, 146:400-413. doi:10.1016/j.envpol.2006.07.003nstein

[28] Walker G, Fairburn J, Smith G, Mitchell G. Environmental quality and social deprivation. R\&D Technical Report E2067/1/TR. Bristol: Environment Agency, 2003.

[29] Weinstein ND. Unrealistic optimism about future life events. J. Pers. Soc. Psychol. 1989, 39(5):806-820. 